\title{
The slow death of the concept of schizophrenia and the painful birth of the psychosis spectrum
}

\author{
S. Guloksuz ${ }^{1,2}$ and J. van $\mathrm{Os}^{1,3,4 *}$ \\ ${ }^{1}$ Department of Psychiatry and Psychology, Maastricht University Medical Centre, Maastricht, the Netherlands \\ ${ }^{2}$ Department of Psychiatry, Yale University School of Medicine, New Haven, CT, USA \\ ${ }^{3}$ Department of Psychiatry, Brain Centre Rudolf Magnus, University Medical Centre Utrecht, Utrecht, the Netherlands \\ ${ }^{4}$ Department of Psychosis Studies, King's College London, King's Health Partners, Institute of Psychiatry, London, UK
}

The concept of schizophrenia only covers the $30 \%$ poor outcome fraction of a much broader multidimensional psychotic syndrome, yet paradoxically has become the dominant prism through which everything 'psychotic' is observed, even affective states with mild psychosis labelled 'ultra-high risk' (for schizophrenia). The inability of psychiatry to frame psychosis as multidimensional syndromal variation of largely unpredictable course and outcome - within and between individuals - hampers research and recovery-oriented practice. 'Psychosis' remains firmly associated with 'schizophrenia', as evidenced by a vigorous stream of high-impact but non-replicable attempts to 'reverse-engineer' the hypothesized biological disease entity, using case-control paradigms that cannot distinguish between risk for illness onset and risk for poor outcome. In this paper, the main issues surrounding the concept of schizophrenia are described. We tentatively conclude that with the advent of broad spectrum phenotypes covering autism and addiction in DSM5, the prospect for introducing a psychosis spectrum disorder - and modernizing psychiatry - appears to be within reach.

Received 3 January 2017; Revised 1 June 2017; Accepted 2 June 2017; First published online 10 July 2017

Key words: Classification, clinical staging, diagnosis, DSM, outcome, psychosis spectrum disorder.

Ever since its conception, 'schizophrenia' has been an 'essentially contested concept' (Geekie \& Read, 2009). Debates at (European) mental health conferences invariably end with around $50 \%$ in favour of abandoning the term, and $50 \%$ in favour of the status quo. This divide has become the implicit hallmark of academic psychiatry: a science in search of solid data to back up its early 20th century nosological outlook on mental variation. For decades, biological approaches have been tested in an attempt to essentially 'reverse-engineer' the hypothesized disease entity, using the classical case-control comparison. However, despite many claims of success ('genes for schizophrenia', 'cognitive illness', 'brain disease'), biological findings in psychiatry, whilst fascinating, are fuzzy and unreliable (Ioannidis, 2005), and do not suggest categorical distinctions (Kapur et al. 2012).

Schizophrenia represents the $30 \%$ poor outcome of a much broader spectrum of psychotic disorders (Perala et al. 2007). It is at least 10 times more researched than the other $70 \%$ of the clinical psychosis spectrum (van Os, 2016) and basically has come to represent everything 'psychotic' - even those with subtle experiences

\footnotetext{
* Address for correspondence: Jim van Os, Department of Psychiatry, University Medical Centre Utrecht, PO BOX 85500, 3508 GA Utrecht.

(Email: vanosj@gmail.com)
}

of psychosis in the context of anxiety and depression, said to be at 'Ultra High Risk' (of schizophrenia) (Van Os \& Guloksuz, 2017).

The question that we-prudently and constructively attempt to address in this article is: should psychiatry continue to look at human variation through the 'schizo'-prism, as embedded in major classification systems, or can an alternative case be made that makes more sense, both in clinical practice and in research?

\section{The devolution of the concept of schizophrenia}

'We stand atop a long tradition of clinical descriptive research and 'authority-based' diagnostic systems, in which, in the struggle for dominance of psychiatric nosologies, the most famous and articulate professor won.' (Kendler, 2016b).

The concept of schizophrenia has - not - evolved since Kraepelin coined the term 'dementia praecox' about a century ago. Kraepelin first conceptualized dementia praecox and manic-depressive psychosis as two distinct natural disease entities; Bleuler later introduced the term 'schizophrenia' for the first time in his monograph: 'Dementia Praecox or the Group of Schizophrenias' (Jablensky, 2010). Based on his extensive clinical work with patients, Bleuler challenged the gloomy viewpoint of dementia praecox: Progressive deterioration to dementia and early onset were neither exclusive nor uniform to justify a discrete disease category. In contrast to 
Kraepelin's narrow perspective of dementia praecox, limited to the most severe clinical representation, he adopted a much broader approach that expanded the boundaries of schizophrenia to incorporate a continuum phenotype from latent schizotypy and schizophrenia (Jablensky, 2010). Early efforts to classifying mental disorders in the USA - largely influenced by the mainstream psychoanalytical formulation - embraced Bleuler's broad and more psychologically-oriented concept of schizophrenia until the release of the third edition of the Diagnostic and Statistical Manual of Mental Disorders (DSM-III) (Andreasen, 1989). The DSM-III, preceding endeavours to increase the reliability of psychiatric diagnoses in research, e.g. the Research Diagnostic Criteria and Feighner Criteria, introduced a 'mutated' Kraepelinian diagnostic practice that was substantially influenced by Langfeldt's poor outcome schizophrenia theory and Schneider's first rank symptoms. One of the main driving forces for the neo-Kraepelinian movement was the disappointment with low reliability hindering collaborative research efforts (Dutta et al. 2007). The widespread use of antipsychotics with serious - sometimes irreversible and even life-threatening - side effects also necessitated this narrow diagnostic convention to improve the risk-benefit ratio of antipsychotics by limiting the treatment to the most severe and chronic manifestations of illness (Andreasen, 1989). This progressive movement-cutting all ties with psychoanalysis and emphasizing the importance of psychiatric nosology akin to European practice - were welcomed across the pond (Murray, 1979). However, this revolution in psychiatry, like other radical shifts in history, has subsequently evolved into a dogma per se that ignores all criticisms. Sailing before the wind of biological psychiatry, data of which are applied in attempts to reverse-engineer the narrow concept of schizophrenia, seeded first in the USA, has dominated the field over the last 40 years (Dutta et al. 2007).

\section{The outcome bias}

'Schizophrenia is heterogeneous. Some patients with the disorder do well at follow-up and should not, for this alone, be regarded as misdiagnosed.' (McGlashan, 1988)

Robins and Guze (pioneers of the DSM-III) concluded: 'good prognosis "schizophrenia" is not mild schizophrenia, but a different illness' (Robins \& Guze, 1970). However, evidence suggests that the schizophrenia construct is subject to Berkson's bias, which is a specific type of selection bias that occurs when the research sample is limited to help-seeking populations, particularly when the research is carried out at specialized tertiary centres. The restrictive construct of schizophrenia, particularly emphasizing chronicity and deterioration, filters out less severe cases with good prognosis and leads to morbidity concentration (Cohen \& Cohen, 1984) (Fig. 1). This 'enriched' sample of severely ill patients with poor outcome represents only a fraction of the broader phenotype that includes a variety of psychosis spectrum diagnostic categories such as schizophreniform disorder, delusional disorder, brief psychotic disorder and so on (Perala et al. 2007). Prospective studies of patients with an initial diagnosis of schizophrenia indicate a vast amount of outcome heterogeneity within and between patients (Harding et al. 1987; Allardyce \& van Os, 2010). Patients with better outcome either never enter, or eventually drop out of mental health care: They either recover and do not necessitate mental health treatment or display a favourable illness course and thus no longer fit into the schizophrenia definition per current classification systems.

Thus, the biased cluster of diagnosed help-seeking patients shares similarities that are discretely associated with poor outcome but are not necessarily expressed across the whole phenotypic spectrum (van Os et al. 1997; Zipursky et al. 2013). Researchers searching for indices of deterioration, akin to Kraepelin's dementia praecox, may have failed to demonstrate such neurodegeneration, but their remarks albeit within a different context - were accurate: 'The 'true' natural history of an illness cannot be determined from studies in treated populations' (Waddington et al. 1997).

Considering major advances in mental health care, a linear increase in good outcome would logically be anticipated. However, a meta-analysis of outcome studies of schizophrenia in the last century demonstrated that a biphasic pattern exists, not as a function of improvement in treatment but as a function of diagnostic trends (Hegarty et al. 1994). The steady rising trend in the proportion of patients with a favourable outcome, which saw a remarkable twofold increase to around $50 \%$ after the introduction of antipsychotics in the 1950s and 1960s, came to an end after the 1970s when the broad definition of schizophrenia was replaced with stringent diagnostic criteria, initiating a downward trend, with a drop of $15 \%$ by 1990 (Hegarty et al. 1994). Findings indicate that the narrow definition of schizophrenia is significantly associated with a decline in the rates of patients with a favourable outcome (McGlashan, 1988). Studies using the Kraepelinian diagnostic systems also found lower but not statistically significant recovery estimates in comparison to non-Kraepelinian samples (median of $9 \%$ v. 12.5\%) (Jaaskelainen et al. 2013). Contrary to expectations, more recent findings from the 10-year follow-up of the Suffolk County Mental Health Project cohort showed no significant improvement in the rate of 

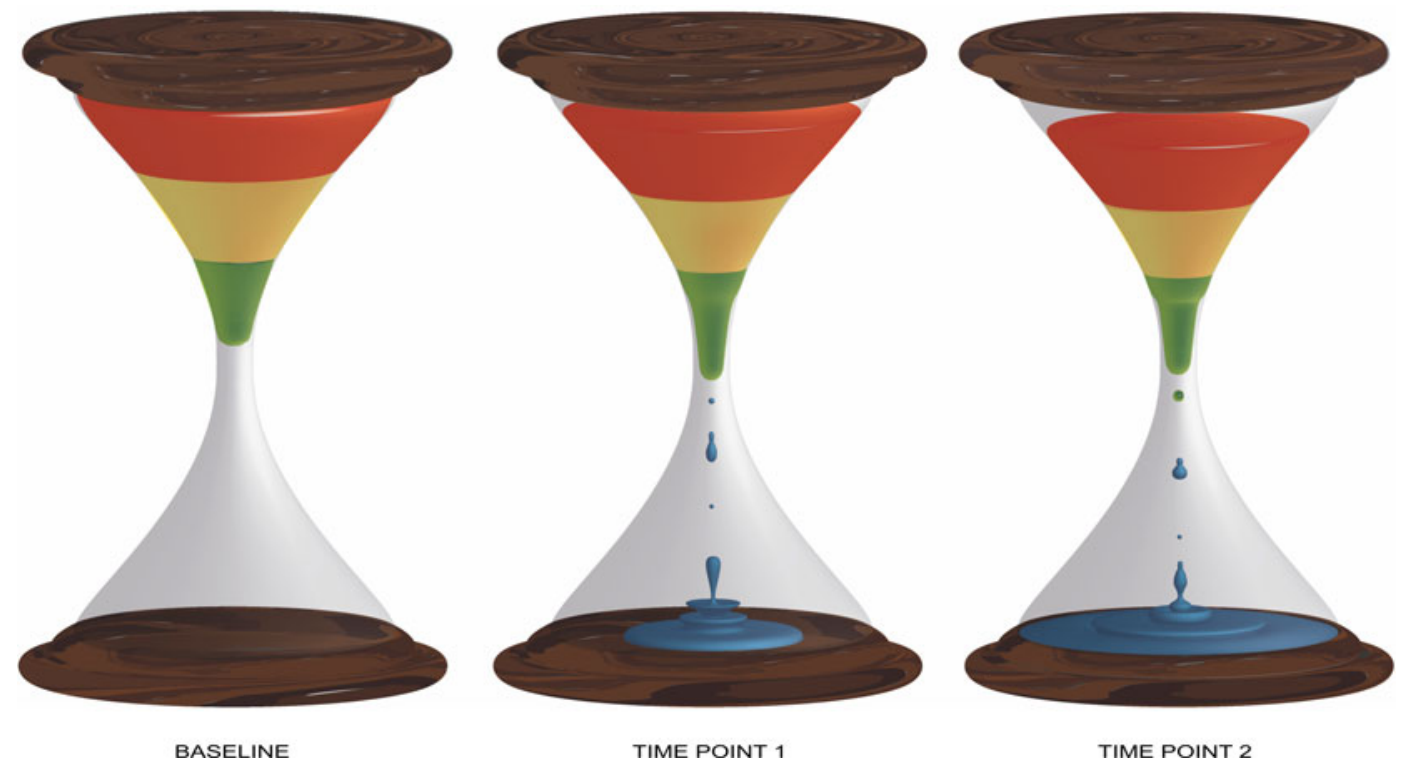

Fig. 1. Depicts the morbidity concentration in an inception cohort of first episode psychosis over a period. The relative balance between poor (red), intermediate (yellow) and favourable outcome (green) shifts towards poor outcome as a fraction of the patients with favourable outcome (green) either recover or no longer meet diagnostic criteria for schizophrenia (blue).

favourable outcome compared with those in previous samples (Bromet et al. 2005). The investigators argued that the lack of progress might be attributed to the nosological switch from the broader schizophrenia concept in DSM-II to a narrowly defined chronic schizophrenia in DSM-III, as well as the influence of Berkson's bias.

Inclusiveness of diagnostic criteria appears to be a significant confounder in studies of predictors for outcome, such as in the case of the higher male/female ratio in patients with an unfavourable outcome as a function of more restrictive diagnostic systems (Castle et al. 1993). Similarly, enriched samples of poor outcome spuriously find a more co-occurrence of positive and negative symptom domains, thus creating a false conception of a distinct illness, when in fact an inflated rate of concurrence has been the individual contribution of each dimension to help-seeking behaviour (Maric et al. 2004).

Meta-analyses report that male sex is associated with a 1.3-1.5-fold increase in the risk of developing schizophrenia (Aleman et al. 2003; McGrath et al. 2004). Similar to the outcome bias, the sex difference in incidence rates were significantly higher in studies with samples collected in the post-DSM-III era compared with those collected prior to 1980 (Aleman et al. 2003) - apparently as a result of the use of more stringent diagnostic criteria (Lewine et al. 1984; Castle et al. 1993; Beauchamp \& Gagnon, 2004). Conversely, no statistically significant sex difference exists in prevalence estimates of schizophrenia (Saha et al. 2005; Perala et al. 2007). Aside from methodological issues
(Saha et al. 2008), the ebb of male preponderance in prevalence estimates, contrasting with comparable incidence rates, could be interpreted with two propositions: (i) Male sex predicts both development of schizophrenia and either better outcome or greater illness-related mortality during the course. However, evidence indicates no sex-difference in standardized mortality ratios (Saha et al. 2007) and better outcome in women diagnosed with schizophrenia (Abel et al. 2010). (ii) Clinicians, guided by diagnostic manuals with rigid criteria, erroneously tend to overdiagnose schizophrenia in males at first contact. With this discussion, our aim was not to disentangle this paradox but to prompt researchers about how different definitions can dramatically influence even basic demographic and epidemiological parameters underlying a disease concept.

\section{Psychosis continuum}

Modern classification systems, embracing a polythetic approach, categorize schizophrenia and related disorders based on different combinations of a required number of symptom domains that exceed the operational threshold of severity. This taxonomy implies a point of rarity, a unique phenotype with precise boundaries. However, a systematic review of taxometric research on schizophrenia concluded that studies favouring a categorical construct over a single distribution model were heavily influenced by a variety of methodological issues endangering the external and the internal validity (Linscott et al. 2010). 
Consecutive meta-analyses of modern epidemiological data further suggest that psychosis expression is not an all-or-none phenomenon, but, in fact, phenomenologically and temporally continuous across the general population, with prevalence rates of subthreshold states varying from around 5\% (delimited to interview-based reporting) to $8 \%$ (including selfreport estimates) and incidence rates of $2.5 \%$ (van Os et al. 2009; Linscott \& van Os, 2013). With regard to temporal continuity, psychotic experiences at a subclinical level in adolescence and early adulthood have some predictive value for psychotic disorders and also, to a lesser degree, for non-psychotic disorders, but mainly for a more severe psychopathology: functional impairment, violence and suicide (Poulton et al. 2000; Hanssen et al. 2005; Rossler et al. 2007; Dominguez et al. 2010, 2011; Saha et al. 2011; Kaymaz et al. 2012; Kelleher et al. 2012; Werbeloff et al. 2012; Sharifi et al. 2015; Honings et al. 2016a, b). Recent findings from World Health Organization World Mental Health Surveys showing bidirectional temporal associations between positive psychotic experiences and a broad spectrum of non-psychotic mental disorders concur with the notion that subtle psychosis expression is transdiagnostic (McGrath et al. 2016).

Psychotic experiences are generally (almost over three-fourths) transient (Hanssen et al. 2005; Cougnard et al. 2007). However, the likelihood of later psychopathology that requires professional care increases as a function of the additive interaction between subthreshold expression of multiple psychotic symptom domains - for example, the co-occurrence of hallucinations and delusions predicts higher psychopathology load and greater severity (Smeets et al. 2012; Nuevo et al. 2013; Smeets et al. 2013). Similarly, the greater the admixture with affective disturbance (Hanssen et al. 2005) or motivational impairments (Dominguez et al. 2010), the greater the risk of psychotic disorder in the future. The presence of psychosis can thus be considered as a marker for more severe psychopathology that negatively impacts outcome. To what degree psychosis itself, rather than the severity of the mixed psychopathological states it forms a part of, causally impacts outcome remains uncertain.

Evidence that environmental and genetic load are shared across clinical and subthreshold psychotic phenomena lend further support for aetiological continuity and provides us with a framework to dissect diverse paths from transitory psychotic experiences to persistent psychosis expression and subsequent need for care. Studies have shown that genetic liability and exposure to environmental risk factors (trauma, urban environment, cannabis, etc.) synergistically increase psychosis expression - as a function of the severity of comorbid psychopathology - in a dose-response fashion (Guloksuz et al. 2015) and further predicts subsequent persistence and need for care in those with baseline subthreshold psychotic experience (Henquet et al. 2004; Spauwen et al. 2004, 2006a, b).

Instead of a binary model, the liability-threshold model (Gottesman \& Shields, 1967), providing a basis to predict phenotypic outcome quantitatively by the cumulative risk load of genetic and environmental factors, might be advantageous in investigating psychosis expression lying on the same continuum with normality (Fig. 2).

\section{Transdiagnostic psychosis manifestation}

\begin{abstract}
'If we were to accept that the affective and schizophrenic manifestations of insanity are not in themselves the external expression of certain disease processes, but merely reveal those areas of our personality in which such processes take place, ... [t]heir significance would then only reside in the fact that the schizophrenic illnesses affect different parts of our emotional life from the manicdepressive insanity.' (Kraepelin, 1992)
\end{abstract}

A spectrum model of psychosis has testable implications (e.g. across the psychosis spectrum there are no qualitative differences in psychopathology, aetiology, treatment and outcome; there is movement over the spectrum and across dimensions within individuals), many of which are supported by the existing literature. Thus, similarities between schizophrenia and bipolar disorder exceed their differences: phenomenological expression (van Os et al. 2000; Krabbendam et al. 2004; Kaymaz et al. 2007), cognitive functioning (Bora et al. 2009; Hill et al. 2013), genetic liability (Van Snellenberg \& de Candia, 2009; Ritsner \& Gottesman, 2011; Lee et al. 2013; van Os et al. 2017) and possible neuroanatomical correlates (Ivleva et al. 2013; Goodkind et al. 2015). Recent efforts to discriminate the DSM categories of bipolar disorder and schizophrenia using a multimodal set of biomarkers (cognition, evoked potentials, anti-saccadic eye movement and neuroimaging) failed to yield a desirable outcome (Tamminga et al. 2013). Clinical data suggest that bipolar disorder and schizophrenia lie at distant ends of a severity continuum, with schizoaffective being in the middle (Mancuso et al. 2015). Also, in help-seeking samples said to show 'Clinical High Risk', mood and anxiety disorders commonly coexist with subthreshold psychotic symptoms, anticipating relatively unfavourable prognosis (Perlis et al. 2011; Wigman et al. 2014), questionably framed as 'clinical transition' (Fusar-Poli et al. 2014).

Similar to data in clinical populations, a significant, albeit relatively weaker, association between dimensions of affective disturbance and psychotic expression has been shown in general population studies (Krabbendam et al. 2004; van Rossum et al. 2011; 


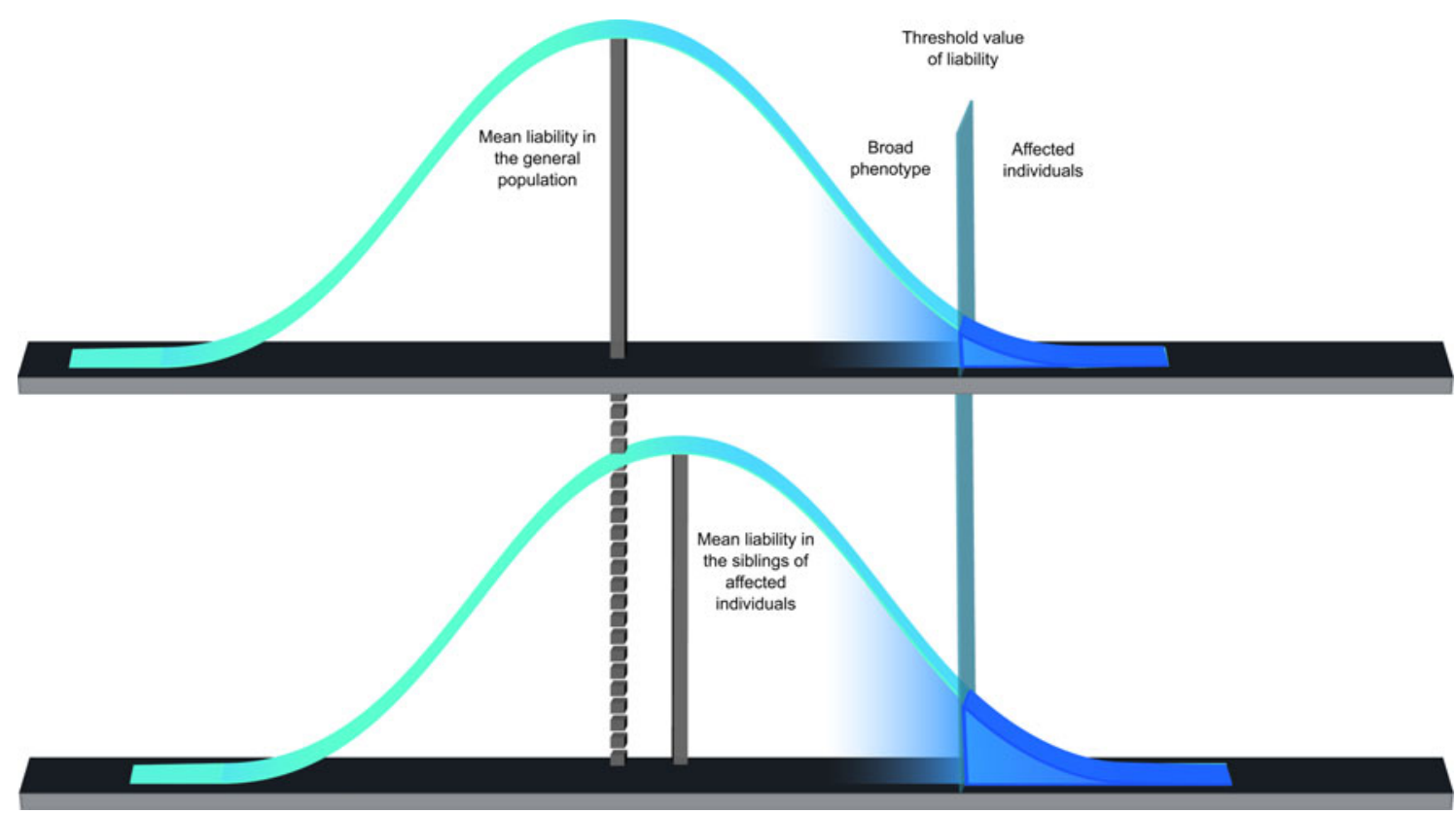

Fig. 2. The liability-threshold model, assuming a Gaussian distribution of a continuous liability in the general population, posits phenotypic outcome can be determined quantitatively by the combined effects of genetic load and environmental factors. If cumulative predisposition exceeds a certain threshold value, individual manifests the clinical syndrome.

Wigman et al. 2011). Epidemiological data further show that affective dysregulation and psychosis expression, with greater exposure to environmental risk factors, interact with each other, giving rise to a more severe outcome (Hanssen et al. 2005; Kaymaz et al. 2007; Wigman et al. 2012; Guloksuz et al. 2015; Isvoranu et al. 2016).

These findings might be more suggestive of a unitary model of psychosis. Bipolar disorder and schizophrenia may well be different expressions (phenotypic presentations) of a substantially shared pathoaetiology, with varying outcomes due to disease modifiers (e.g. neurodevelopmental impairment), rather than two distinct entities with entirely diverse pathoaetiological processes (Murray et al. 2004). There are indeed various examples in medicine, such as multiple sclerosis, following distinct illness patterns (clinically isolated syndrome, relapsing-remitting, secondary progressive and primary progressive) with varying symptoms and outcomes but stemming from the same pathoaetiology (Confavreux \& Vukusic, 2006; Lublin et al. 2014). Figure 3 illustrates illness course across different types of multiple sclerosis; in brackets, the DSM-IV diagnostic categories (Brief Psychotic Episode, Bipolar Disorder, Schizoaffective Disorder and Schizophrenia) were given on the basis of the resemblance of putative illness course. Similar to multiple sclerosis, these different psychiatric conditions may reasonably belong to the same spectrum of illness. Accordingly, a recent line of work suggests the existence of a general transdiagnostic psychosis phenotype at both subclinical and clinical levels - coinciding across the psychosis spectrum: schizophrenia, schizoaffective disorder and bipolar disorder - encompassing affective and non-affective symptoms, with five symptom dimensions (positive and negative symptoms, mania, depression and disorganization) disentangling the heterogeneity (Reininghaus et al. 2013, 2016; Shevlin et al. 2017). Originally, DSM5 was set up to encompass the model of psychotic disorders pertaining to a spectrum with transdiagnostic dimensions to allow for diagnosing heterogeneity; however, halfway the process, the idea of transdiagnostic dimensions was abandoned.

From a researcher's standpoint, an artificial categorization leads to a considerable loss of power and precision (Kraemer, 2007); from a clinician's standpoint, categories based on illness course - regardless if they are different types of the same illness or not - are pragmatically necessary to determine treatment strategy. The category of schizophrenia-type psychosis, confined to the most severely ill patients with poor outcome, may be beneficial in approximating need for care, outcome, course and treatment (Kendell \& Jablensky, 2003). However, mounting evidence suggests that a transdiagnostic dimensional approach, complementary to the clinical utility of the categorical approach, may provide in-depth information that covers different aspects of psychopathology beyond the borders of the modern operationalized criteria (Demjaha et al. 2009; Russo et al. 2014; van Os \& Reininghaus, 2016). 
(a)

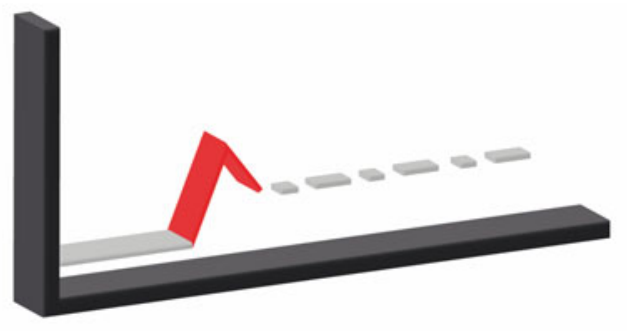

(b)

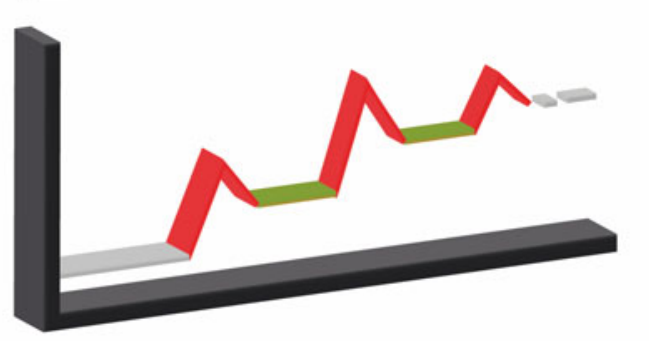

(c)

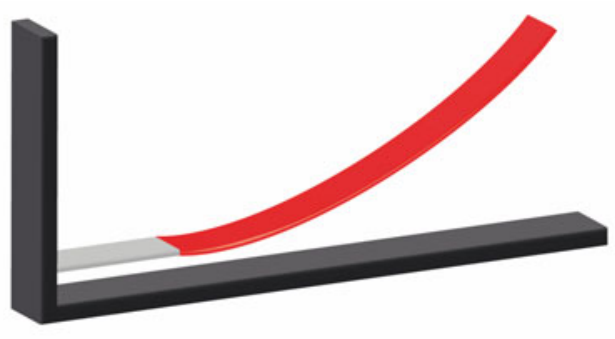

(d)

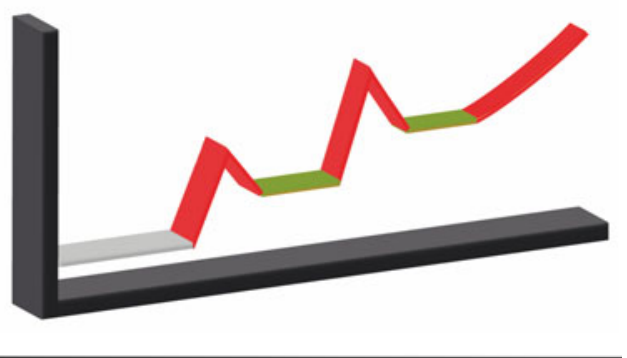

TIME

Fig. 3. Shows current multiple sclerosis classification based on disease progression. The colour red represents active disease; colour green represents remission. In brackets, the DSM-IV diagnostic categories were listed based on the resemblance of putative illness course. (a) Clinically Isolated Syndrome (Brief Psychotic Disorder), (b) Relapsing-remitting Multiple Sclerosis (Bipolar Disorder), (c) Primary Progressive Multiple Sclerosis (Schizophrenia), (d) Secondary Progressive Multiple Sclerosis (Schizoaffective Disorder).

One of the clinically-derived arguments for Kraepelinian dichotomy is that patients with bipolar disorder respond to lithium, whereas patients with non-affective psychosis do not. However, affective symptoms respond to lithium dimensionally, i.e. affective symptoms in the context of schizophrenia (i.e. schizo-affective disorder) also respond to lithium. In regard to this groundless notion of splitting and lumping of disorders on the basis of response to treatment, one may also declare the opposite, namely that these two phenotypes are identical based on the fact that they both respond to treatment with secondgeneration antipsychotics. In addition, cyclic illness course characterized by full remission between episodes predicts response far better than both categorical diagnoses (Tighe et al. 2011). There is no doubt that this represents very useful information for treating clinicians, but it is a reductionist fallacy to propose these observations as the reasoning behind splitting or unifying the two conditions.

A lack of diagnostic markers in psychiatry impedes an objective classification. In this regard, current artificial boundaries drift the field to a paradox by hindering efforts to develop novel diagnostic tools, essential for a classification system grounded in theory. Research practice should resist the temptation of clinical pragmatism and better move away from the dichotomous approach to set sail for an evidencebased diagnostic practice replacing the century-old construct. Indeed, this was the reasoning behind the Research Domain Criteria (RDoC) system, introduced by the National Institute of Mental Health (NIMH) (Cuthbert \& Insel, 2010).

\section{Schizophrenia is an obstacle to aspirational work of early intervention}

'There is no dark side of the moon really. Matter of fact it's all dark. The only thing that makes it look light is the sun' (in 'Eclipse', a song by Pink Floyd from the album: The Dark Side of the Moon)

Diagnostic manuals are like standard operating procedures: they simplify the decision-making process and guide clinicians to approximate diagnosis when valid and specific measures are not available or readily accessible to ascertain pathoaetiology. Therefore, objective diagnostic tools or lack thereof are critical for validating the diagnosis. At its best, check-listing diagnostic criteria improve reliability. Schizophrenia diagnosis has indeed ensured a high reliability, but as summarized above, its validity is debatable. Over 
the years, the weak validity and specificity of the schizophrenia construct have arisen as a critical methodological issue. As discussed previously, schizophrenia, along with other diagnostic categories, originally formulated to bring order to psychiatric taxonomy, has become reified over time and transformed into an impediment to research (Kendler, 2016a).

Early intervention strategy became entangled in schizophrenia reification by hinging on the prototypic psychotic illness (schizophrenia) (Van Os \& Delespaul, 2005; Fusar-Poli et al. 2014). In keeping with classification manuals, operationalized criteria have been applied to conceptualize the binary model of clinical high-risk state - prodromal stage - as a proxy for schizophrenia. The target population has been identified as individuals with attenuated positive psychotic symptoms or a family history of psychotic disorder.

Adopting a pragmatic model, early intervention efforts have primarily aimed to reduce false discovery rate by implementing a narrow description of clinical high-risk state restricted only to subthreshold positive psychotic symptoms in help-seeking individuals (Miller et al. 2003; Yung et al. 2005). The basic assumption of this indicated prevention, modelled after successful secondary prevention strategies in medicine, is that the detection of early warning symptoms of schizophrenia and subsequent intervention shall prevent subtle psychopathology from transitioning to a manifest clinical syndrome and ultimately reduce functional impairment (Van Os \& Delespaul, 2005).

However, as discussed previously, epidemiological data from different populations have consistently demonstrated that a model based on psychosis expression per se - hallucinations and delusions at a subthreshold level, which are not rare and often transient in the general population - overlooks the dynamic interplay between other elements of psychopathology and may, therefore, be insufficient to predict later psychopathology (Bentall \& Beck, 2004; van Os, 2013). In accordance, over three-fourths of the at-risk population enrolled in The North American Prodrome Longitudinal Study-2 had sought help for nonpsychotic complaints prior to the onset of recognizable psychotic experiences (Woodberry et al. 2016). The initial intent of the prodromal psychosis concept, similar to its point of origin, schizophrenia, is to ascertain the group that benefits most from a therapeutic intervention, and thereby avoid unnecessary treatment (McGorry et al. 2002; McGlashan et al. 2003). However, this conceptualization possesses a danger of giving an implicit message to clinicians in the field that the at-risk population is the 'pre-schizophrenia' group and should be vigorously treated for that reason. Accordingly, a recent survey shows that clinicians follow a more conservative path than guidelines in deciding on dose reduction and discontinuation of antipsychotics after complete remission of the first psychotic episode (Thompson et al. 2016).

Emerging evidence from at-risk samples was a wake-up call to early intervention (Fusar-Poli et al. 2014; McGorry \& Nelson, 2016): (i) The framework of 'transition' as an end result fails to explain the heterogeneity in clinical and functional outcome, (ii) Studies that control for 'false transition' representing natural fluctuation of an existing psychotic state find very low 'transition' rates (Morrison et al. 2012), (iii) An over-reliance on positive psychotic symptoms sets a self-limiting barrier to capture early expression of nonspecific psychopathology, the severity of which is 'marked' but not 'caused' by attenuated psychosis, (iv) 'Clinical High Risk' criteria majorly identify individuals with diagnosed states of anxiety/depression and/ or drug use who also display subtle psychotic experiences, which research has shown is a marker for but not necessarily the cause of - relatively poor outcome (Perlis et al. 2011; Wigman et al. 2014; McAusland et al. 2015). Thus, early treatment of psychopathology (including treatment of subtle psychotic experiences), in states of anxiety/depression/drug use with a degree of psychosis admixture will naturally improve outcome; it does not seem necessary or valid, however, to claim that this effort represents 'prevention of schizophrenia' (Van Os \& Guloksuz, 2017).

Evidently, the aspirational work of early intervention shall evolve by abandoning confusing terminology based on the ill-defined concept of schizophrenia. A universal early intervention strategy in psychiatry, as embedded in the Headspace initiative (McGorry et al. 2016), should be the ultimate - and likely more effective - goal.

\section{The term 'schizophrenia'}

'The way a word is used this year is its phenotype, but it has a deeply seated, immutable meaning, often hidden, which is the genotype.' (Thomas, 1973)

The origin of the term 'schizophrenia' is Greek, meaning 'split mind'. The metamorphosis of the term 'schizophrenia' has been striking: Schizophrenia is now not only a medical term, but also a physics term to describe the split personality of electrons (Chase, 2008) and a widely-used metaphor in economy for an unpredictable market.

The dark view of the current concept of schizophrenia - a distinct, genetic brain disease with a poor course - is also a key factor that further increases stigma and discrimination. Of all diagnostic categories, schizophrenia has been by far the most stigmatized mental condition that generates negative emotions: 
desperation, pity and fear (Lasalvia et al. 2015). Social media research has shown that 'schizophrenia' has been used inappropriately and non-medically with, as expected, the adjective form 'schizophrenic' being even more often negative (Joseph et al. 2015). Until the recent renaming of schizophrenia in Japan, these negative connotations had made clinicians largely reluctant to use the term in their communication with patients and their families (Takahashi et al. 2009). A similar pattern was also observed in other countries, such as Scotland (Allardyce et al. 2000). Although a simple renaming of schizophrenia may forestall its metaphorical use, a semantic revision without a reconceptualization may not be adequate to decrease stigma immediately (Lieberman \& First, 2007; Koike et al. 2016). However, even more important than stigma may be internalised negative expectations associated with schizophrenia (Sullivan et al. 2015) and its pessimistic and unproven 'devastating genetic brain disease' description in the scientific literature (Sawa \& Snyder, 2002). The recently formulated CHIME framework identifies 'hope and optimism' as one of the core conditions for personal recovery (Leamy et al. 2011). The question is to what degree mental health professionals, influenced by a long tradition of pessimistic and mystifying 'schizo' formulations of psychotic illness, provide an environment where patients are met with hope and optimism. More hopeful, and arguably scientifically more valid, alternatives, in the direction of a broad underlying susceptibility, have recently been proposed by those with lived experience of psychosis (George \& Klijn, 2013). The CHIME framework shows a clear need to diagnose not only on the basis of symptoms, but also on the basis of where the person is in the process of personal recovery, starting with the phase of being completely overwhelmed by the illness, to living a meaningful life despite continuing mental challenges.

\section{From rare mental disorder (schizophrenia) to psychosis spectrum disorders: dimensional assessment and multifactorial staging system}

I expect to see the end of the concept of schizophrenia soon. Already the evidence that it is a discrete entity rather than just the severe end of psychosis has been fatally undermined.' (Murray, 2017)

Like all other things, the way we think about mental illness is subject to a set of shared beliefs that can show change over time as a result of, for example, novel scientific insights or persistent calls for change from subgroups with deviant beliefs. In the area of mental health, the shared belief that mental distress comes as diagnosable discrete disease entities increasingly is co-existing with the view that mental suffering in reality represents a series of spectrum phenotypes. The coexistence of beliefs has found its way to the DSM5, in which the idea of mental illness as a spectrum phenotype was emphatically introduced in the areas of autism, substance use and - nearly - personality disorder, but, remarkably, not for psychotic disorder. Thus, in the DSM5 fact sheet of the American Psychiatric Association (2013), it is stated that 'The symptoms of people with Autism Spectrum Disorder will fall on a continuum, with some individuals showing mild symptoms and others having much more severe symptoms. This spectrum will allow clinicians to account for the variations in symptoms and behaviours from person to person'. The introduction of this type of spectrum thinking is remarkable, given that until relatively recently, autism was considered a rare and uniformly severe, poor prognosis mental disorder.

Psychotic phenomena might well be conceptualized as a broad spectrum ranging from mild but persistent schizotypy to severe and recurrent schizophrenia. Indeed, the DSM5 psychosis workgroup attempted to introduce the idea of a spectrum in the structure and the ordering of the chapter, using the level, number and the duration of psychotic signs and symptoms to demarcate psychotic disorders from each other, 'as a stepping-stone towards a more valid classification system' (Heckers et al. 2013). A multimodal investigation of genetic susceptibility at different layers of environmental exposure using the unbiased multidimensional assessment of the psychosis spectrum, not confounded by current diagnostic categories, would contribute to a better understanding of psychotic phenomena. This 'liberated' strategy (Moncrieff \& Middleton, 2015) has a greater probability of generating novel findings and discerning distinct pathological processes that will pave the way for a coherent theory-based classification. For example, if a neurodevelopmental factor predisposes to poor outcome in the psychosis spectrum, this association may not be detectable if the research population is limited to those with poor outcome who may be universally exposed to the neurodevelopmental factor in question. A thorough assessment of symptom dimensions stratified by risk (genetic and environmental) and resilience tiers allows for a true precision medicine in clinical practice. In fact, this is no different than what mental health professionals exercise routinely when they formulate a case.

Current health care practice demands clinicians to make quick decisions under pressure. Therefore, the primary concern with the multidimensional psychosis spectrum approach is whether it will be beneficial or burdensome in the hectic routine of clinical practice involving ever-increasing administrative demands 
and chronic imbalance between clinical load and mental health workforce across the world. Another argument against the utility of this approach is that clinical decisions are often binary not dimensional: admission $v$. discharge or treatment $v$. no treatment.

An additional obstacle stalling the implementation of the dimensional approach in routine practice is the general lack of data verifying its applicability in clinical settings. Therefore, the next step should be to design pragmatic clinical trials testing the utility of the dimensional spectrum approach. These studies may yield data to construct an empirical clinical course staging system that is established on a dimensional formulation of psychopathology across the psychosis spectrum. Clinicians in the field might find this system more familiar and handy in their daily operations: abstract, categorical and more importantly allowing for a bidirectional (up and down) shift between stages/types as opposed to the supposedly static diagnostic categories. The diagnostic stability and consistency of psychotic conditions identified based on current classifications are insufficient, mediocre even for the chronic, poor outcome fraction diagnosed as schizophrenia. Diagnostic switches are common because diagnostic classification often relies on a snapshot of psychopathology, which in reality varies over time. Nevertheless, there are other important longitudinal elements that carry a lot of weight with the clinician's decision, such as the episodic nature - Kraepelin indeed prioritized cyclicity above other factors for discriminating manic-depressive insanity and dementia praecox.

The DSM schizophrenia concept has been criticized for: (i) overreliance on positive symptoms; (ii) negligence of affective, negative and cognitive dimensions; (iii) extraneous emphasis on Schneiderian first-rank symptoms and subtyping, which were both removed in the DSM5; and (iv) incompetency in overcoming heterogeneity (the polythetic structure of the operational criteria further complicating the matter). The value of the negative symptom domain for diagnosis has been consistently demonstrated in empirical studies, long before the release of DSM-III (Carpenter et al. 1973) - largely by means of predicting (albeit with relatively low predictive value) poor outcome, poor treatment response, and functional and cognitive impairment (Milev et al. 2005; Ventura et al. 2009). Over the years, the negative symptom domain has become an active area of investigation in psychosis research with hopes of reducing heterogeneity and developing targeted treatment (Kirkpatrick et al. 2006).

Taking the debate on negative symptoms further, the Maryland group conceived an appealing concept to reduce heterogeneity: the deficit subtype of schizophrenia, characterized by persistent primary negative symptoms that are not secondary to depression, mental retardation, positive psychotic symptoms and medication use (Carpenter et al. 1988). There exist some data - mainly from studies conducted by the same group that coined the deficit syndrome - suggesting a distinct disease entity: differences in clinical outcome, risk factors and biological parameters between deficit and non-deficit types of schizophrenia (Kirkpatrick \& Galderisi, 2008).

However, several methodological issues require further deliberation before drawing a conclusion. First, it is extremely difficult to make a valid and reliable distinction between primary and secondary negative symptoms, particularly in the context of enduring symptoms. Second, although the presence of persistent primary negative symptoms has been defined as the core inclusion criterion for deficit syndrome, the influence of exclusion criteria to rule out secondary negative symptoms should also be taken into account while interpreting findings. As a matter of fact, some of the distinct clinical features observed in deficit syndrome might have resulted from the exclusion criteria: lower rates of substance abuse, depressive symptoms, suicidal ideation and severe suspiciousness (Kirkpatrick et al. 2001). Therefore, even if deficit syndrome constitutes a distinct disease entity within schizophrenia; it is difficult to attribute biological and aetiological differences to enduring primary negative symptoms exclusively. If cognitive dysfunction and negative symptoms are associated with the level of functional impairment, this lends further support to the suggestion that the staging strategy and multidimensional approach would work better than the current taxonomy with a fuzzy algorithm. In this regard, the flexible and integrated spectrum approach, employing a staging system for clinical practice and a multidimensional structure for research use, may provide us with the essential framework to elucidate these enmeshed issues giving rise to often frustrating heterogeneity.

The introduction of a staging system across the spectrum of psychosis would produce a durable strategy (McGorry \& van Os, 2013). In modern medicine, staging systems are frequently revised in the light of accumulating evidence about pathoaetiology, technological advancements and progress in treatment. Until a true discovery, these modifications, taking place within the illness spectrum, will not lead to a synthetic reclassification of diagnosis with each revision - the diagnostic category of a patient may artificially change over time with each new release of the current classification systems, e.g. the rise and fall of schizoaffective disorder.

Given apparent flaws of schizophrenia, both complementary and alternative paradigms, bearing a resemblance to our speculations in the current article, 
have been debated for a long time (Strauss \& Gift, 1977; Bentall et al. 1988; Brockington, 1992; Boteva \& Lieberman, 2003; van Os, 2009; Keshavan et al. 2011). Despite a series of demands for reconceptualization, these scholarly communications (in particular, strategies for clinical implementation) have been stuck at the theoretical level. Given the call for a change coming from highly influential scholars, one might ask why these discussions failed to go beyond 'Monday morning quarterbacking'.

There are likely various reasons for this lack of progress, but the most obvious and influential ones in order of importance may be: (i) the influence of the DSM stronghold with a monopoly mentality, killing the competition in advance by not giving them a foothold; (ii) the sunk cost fallacy or, despite clear lack of progress, to continue to cling to the concept, because an enormous amount of funding and time have been invested in understanding schizophrenia over a century.

The idea of schizophrenia as a distinct categorical entity has recently been contested by the release of the NIMH research initiative, the RDoC (Cuthbert \& Insel, 2010); and the multidimensional approach slowly gaining a foothold in the DSM (Heckers et al. 2013). At last, these advances would generate mostneeded funding to foster more research incorporating multidimensional assessment of transdiagnostic samples that would hopefully provide us with essential data for a reconceptualization along spectrum lines.

However, the current construct of schizophrenia still dominates the field as if there is no other reality without its borders, and therefore remains to be an obstruction, which stagnate the efforts to prudent and feasible solutions. Accordingly, limited data exist about how we may feed dimensional assessment into a staging system. For now, instead of repeating the mistake by proposing a radical shift towards a new framework offering unwarranted promises, we can modestly start with following the footsteps of the reconceptualization of autism spectrum disorder: a single umbrella disorder - psychosis spectrum disorder (PSD) - with specifiers. Even this subtle revision will help the field to rethink psychosis without the borders of schizophrenia and therefore clear the way for a better conceptualization in the future.

This unifying approach, however, should not be interpreted as a refutation of likelihood existence of distinct diseases in the broad PSD - deconstruction will eventually lead to a more stable reconstruction. For now, the reconceptualization is merely acknowledging the limits of our knowledge about PSD. Also, the reconceptualization of PSD cannot be complete without a semantic revision - the term 'schizophrenia' should be abolished.

In his self-reflection, looking back at his prolific career spanning over 50 years, Carpenter states that his major regret is his failure to be bold enough in pressing the field for reconstructing schizophrenia (Carpenter, 2017). We can learn from the past and finally show some collective courage to open up the discussion of how we could replace the slowly dying schizophrenia concept.

\section{Conclusion}

Psychosis remains an enigma; despite intensive research, much remains to be elucidated in terms of aetiology, diagnosis and treatment. Given this state of affairs, perpetuating the diagnostic status quo has been the default to date. Furthermore, schizophrenia is a psychiatric tradition as much as a diagnosis, contributing to the identity of diagnosing professionals. In Japan and South Korea, change was perhaps easier as the concept of 'splitting mind disease' was imported from another part of the world, making replacement with a culturally more acceptable concept a viable option. In Europe, the concept of schizophrenia is associated with the origins of scientific psychiatry, something to be proud of, a symbol of progression. However, with the introduction of spectrum phenotypes in DSM5, and an increasingly vocal movement for change (George \& Klijn, 2013; Henderson \& Malhi, 2014; Lasalvia et al. 2015; Moncrieff \& Middleton, 2015) the tipping point may have been reached. Just as schizophrenia was the last diagnosis to benefit from research linking to childhood adversity to adult mental health outcomes (Read \& Bentall, 2012), so may it be the last to benefit from the advantages of a modern spectrum diagnostic approach. There is hope for schizophrenia.

\section{Acknowledgements}

SG and JvO would like to acknowledge the European Community's Seventh Framework Program under grant agreement No. HEALTH-F2-2009-241909 (Project EU-GEI). Authors would like to thank Lotta-Katrin Pries and Ilgin Guloksuz for their help with designing the figures.

\section{Declaration of Interest}

None. 
Summary box

- With the introduction of spectrum phenotypes in DSM5, and an increasingly vocal movement for change, the tipping point may have been reached. Just as schizophrenia was the last diagnosis to benefit from research linking childhood adversity to adult mental health outcomes, so may it be the last to benefit from the advantages of a modern spectrum diagnostic approach.

- The current concept of schizophrenia, described by diagnostic guidelines and later reified, has become detrimental to progress in mental health by confining research efforts to a constantly changing construct that does not exist in Nature.

- The current concept of schizophrenia, subject to Berkson's bias, represents only a minor fraction with the worst outcome of a much broader and under-researched spectrum phenotype, yet has come to represent everything 'psychotic' - even psychotic experiences in non-psychotic disorders ('Ultra-High Risk').

- The current concept of schizophrenia overlooks evidence indicating that psychosis expression is continuous across the general population and can, therefore, be better explored using a quantitative dimensional approach than a dichotomous distinction between ill and healthy on the basis of arbitrary set points.

- The current concept of schizophrenia is far from being specific, as evidenced by the significant overlap between schizophrenia and other diagnostic constructs, concerning treatment, phenomenological expression, genetic liability, molecular mediation and anatomical representation.

- The current concept of schizophrenia, dictated by recent diagnostic manuals, is inadequate - even misleading at times - to convey an in-depth information to guide clinicians and patients in the decision-making process.

- The current concept of schizophrenia, as the prototypic psychotic illness, sets a self-limiting barrier to aspirational work of early intervention.

- The current concept of schizophrenia has led to the transformation of a medical term to a loaded layman's term with various negative connotations.

- The current concept of schizophrenia represents iatrogenic hopelessness ('devastating genetic brain disease'), resulting in internalized negative expectations and undermining the CHIME framework guiding mental health services development.

\section{References}

Abel KM, Drake R, Goldstein JM (2010). Sex differences in schizophrenia. International Review of Psychiatry 22, 417428.

Aleman A, Kahn RS, Selten JP (2003). Sex differences in the risk of schizophrenia: evidence from meta-analysis. Archives of General Psychiatry 60, 565-571.

Allardyce J, Morrison G, Van Os J, Kelly J, Murray RM, McCreadie RG (2000). Schizophrenia is not disappearing in south-west Scotland. British Journal of Psychiatry 177, 38-41.

Allardyce J, van Os J (2010). The natural history of the course and outcome of schizophrenia. In Advances in Schizophrenia Research 2009 (ed. W. F. Gattaz, G. Busatto), pp. 51-65. Springer New York: New York, NY.

American Psychiatric Association (2013). DSM-5 Fact Sheets. (https://www.psychiatry.org/psychiatrists/practice/dsm/ educational-resources/dsm-5-fact-sheets). Accessed 1 January 2017.

Andreasen NC (1989). The American concept of schizophrenia. Schizophrenia Bulletin 15, 519-531.

Beauchamp G, Gagnon A (2004). Influence of diagnostic classification on gender ratio in schizophrenia - a meta-analysis of youths hospitalized for psychosis. Social Psychiatry and Psychiatric Epidemiology 39, 1017-1022.

Bentall RP, Beck AT (2004). Madness Explained: Psychosis and Human Nature. Penguin Books: London.

Bentall RP, Jackson HF, Pilgrim D (1988). Abandoning the concept of 'schizophrenia': some implications of validity arguments for psychological research into psychotic phenomena. British Journal of Clinical Psychology 27(Pt 4), 303-324.

Bora E, Yucel M, Pantelis C (2009). Cognitive functioning in schizophrenia, schizoaffective disorder and affective psychoses: meta-analytic study. British Journal of Psychiatry 195, 475-482.

Boteva K, Lieberman J (2003). Reconsidering the classification of schizophrenia and manic depressive illness--a critical analysis and new conceptual model. World Journal of Biological Psychiatry 4, 81-92.

Brockington IF (1992). Schizophrenia: yesterday's concept. European Psychiatry 7, 203-207.

Bromet EJ, Naz B, Fochtmann LJ, Carlson GA, Tanenberg-Karant M (2005). Long-term diagnostic stability and outcome in recent first-episode cohort studies of schizophrenia. Schizophrenia Bulletin 31, 639-649.

Carpenter WT (2017). Fifty years: do over or move forward. Schizophrenia Bulletin 43, 257-259.

Carpenter Jr. WT, Heinrichs DW, Wagman AM (1988). Deficit and nondeficit forms of schizophrenia: the concept. American Journal of Psychiatry 145, 578-583.

Carpenter Jr. WT, Strauss JS, Bartko JJ (1973). Flexible system for the diagnosis of schizophrenia: report from the WHO International Pilot Study of Schizophrenia. Science 182, 1275-1278.

Castle DJ, Wessely S, Murray RM (1993). Sex and schizophrenia: effects of diagnostic stringency, and 
associations with and premorbid variables. British Journal of Psychiatry 162, 658-664.

Chase R (2008). Schizophrenia is a disease, so electrons aren't at risk. Nature 451, 127.

Cohen P, Cohen J (1984). The clinician's illusion. Archives of General Psychiatry 41, 1178-1182.

Confavreux C, Vukusic S (2006). Natural history of multiple sclerosis: a unifying concept. Brain 129, 606-616.

Cougnard A, Marcelis M, Myin-Germeys I, De Graaf R, Vollebergh W, Krabbendam L, Lieb R, Wittchen HU, Henquet C, Spauwen J, Van Os J (2007). Does normal developmental expression of psychosis combine with environmental risk to cause persistence of psychosis? A psychosis proneness-persistence model. Psychological Medicine 37, 513-527.

Cuthbert BN, Insel TR (2010). Toward new approaches to psychotic disorders: the NIMH Research Domain Criteria project. Schizophrenia Bulletin 36, 1061-1062.

Demjaha A, Morgan K, Morgan C, Landau S, Dean K, Reichenberg A, Sham P, Fearon P, Hutchinson G, Jones PB, Murray RM, Dazzan P (2009). Combining dimensional and categorical representation of psychosis: the way forward for DSM-V and ICD-11? Psychological Medicine 39, 1943-1955.

Dominguez MD, Saka MC, Lieb R, Wittchen HU, van Os J (2010). Early expression of negative/disorganized symptoms predicting psychotic experiences and subsequent clinical psychosis: a 10-year study. American Journal of Psychiatry 167, 1075-1082.

Dominguez MD, Wichers M, Lieb R, Wittchen HU, van Os J (2011). Evidence that onset of clinical psychosis is an outcome of progressively more persistent subclinical psychotic experiences: an 8-year cohort study. Schizophrenia Bulletin 37, 84-93.

Dutta R, Greene T, Addington J, McKenzie K, Phillips M, Murray RM (2007). Biological, life course, and cross-cultural studies all point toward the value of dimensional and developmental ratings in the classification of psychosis. Schizophrenia Bulletin 33, 868-876.

Fusar-Poli P, Yung AR, McGorry P, van Os J (2014). Lessons learned from the psychosis high-risk state: towards a general staging model of prodromal intervention. Psychological Medicine 44, 17-24.

Geekie J, Read J (2009). Making Sense of Madness: Contesting the Meaning of Schizophrenia. Routledge: New York, NY.

George B, Klijn A (2013). A modern name for schizophrenia (PSS) would diminish self-stigma. Psychological Medicine 43, 1555-1557.

Goodkind M, Eickhoff SB, Oathes DJ, Jiang Y, Chang A, Jones-Hagata LB, Ortega BN, Zaiko YV, Roach EL, Korgaonkar MS, Grieve SM, Galatzer-Levy I, Fox PT, Etkin A (2015). Identification of a common neurobiological substrate for mental illness. JAMA Psychiatry 72, 305-315.

Gottesman II, Shields J (1967). A polygenic theory of schizophrenia. Proceedings of the National Academy of Sciences of the United States of America 58, 199-205.

Guloksuz S, van Nierop M, Lieb R, van Winkel R, Wittchen HU, van Os J (2015). Evidence that the presence of psychosis in non-psychotic disorder is environment- dependent and mediated by severity of non-psychotic psychopathology. Psychological Medicine 45, 2389-2401.

Hanssen M, Bak M, Bijl R, Vollebergh W, van Os J (2005). The incidence and outcome of subclinical psychotic experiences in the general population. British Journal of Clinical Psychology 44, 181-191.

Harding CM, Zubin J, Strauss JS (1987). Chronicity in schizophrenia: fact, partial fact, or artifact? Hospital and Community Psychiatry 38, 477-486.

Heckers S, Barch DM, Bustillo J, Gaebel W, Gur R, Malaspina D, Owen MJ, Schultz S, Tandon R, Tsuang M, Van Os J, Carpenter W (2013). Structure of the psychotic disorders classification in DSM-5. Schizophrenia Research 150, 11-14.

Hegarty JD, Baldessarini RJ, Tohen M, Waternaux C, Oepen G (1994). One hundred years of schizophrenia: a meta-analysis of the outcome literature. American Journal of Psychiatry 151, 1409-1416.

Henderson S, Malhi GS (2014). Swan song for schizophrenia? Australian and New Zealand Journal of Psychiatry 48, 302-305.

Henquet C, Krabbendam L, Spauwen J, Kaplan C, Lieb R, Wittchen H-U, van Os J (2004). Prospective cohort study of cannabis use, predisposition for psychosis, and psychotic symptoms in young people. BMJ 330, 11.

Hill SK, Reilly JL, Keefe RS, Gold JM, Bishop JR, Gershon ES, Tamminga CA, Pearlson GD, Keshavan MS, Sweeney JA (2013). Neuropsychological impairments in schizophrenia and psychotic bipolar disorder: findings from the Bipolar-Schizophrenia Network on Intermediate Phenotypes (B-SNIP) study. American Journal of Psychiatry 170, 1275-1284.

Honings S, Drukker M, Groen R, van Os J (2016a). Psychotic experiences and risk of self-injurious behaviour in the general population: a systematic review and meta-analysis. Psychological Medicine 46, 237-251.

Honings S, Drukker M, van Nierop M, van Winkel $R$, Wittchen HU, Lieb R, Ten Have M, de Graaf R, van Dorsselaer S, van Os J (2016b). Psychotic experiences and incident suicidal ideation and behaviour: disentangling the longitudinal associations from connected psychopathology. Psychiatry Research 245, 267-275.

Ioannidis JP (2005). Why most published research findings are false. PLoS Medicine 2, e124.

Isvoranu AM, Borsboom D, van Os J, Guloksuz S (2016). A network approach to environmental impact in psychotic disorder: brief theoretical framework. Schizophrenia Bulletin 42, 870-873.

Ivleva EI, Bidesi AS, Keshavan MS, Pearlson GD, Meda SA, Dodig D, Moates AF, Lu H, Francis AN, Tandon N, Schretlen DJ, Sweeney JA, Clementz BA, Tamminga CA (2013). Gray matter volume as an intermediate phenotype for psychosis: Bipolar-Schizophrenia Network on Intermediate Phenotypes (B-SNIP). American Journal of Psychiatry 170, 1285-1296.

Jaaskelainen E, Juola P, Hirvonen N, McGrath JJ, Saha S, Isohanni M, Veijola J, Miettunen J (2013). A systematic review and meta-analysis of recovery in schizophrenia. Schizophrenia Bulletin 39, 1296-1306.

Jablensky A (2010). The diagnostic concept of schizophrenia: its history, evolution, and future prospects. Dialogues in Clinical Neuroscience 12, 271-287. 
Joseph AJ, Tandon N, Yang LH, Duckworth K, Torous J, Seidman LJ, Keshavan MS (2015). \#Schizophrenia: use and misuse on Twitter. Schizophrenia Research 165, 111-115.

Kapur S, Phillips AG, Insel TR (2012). Why has it taken so long for biological psychiatry to develop clinical tests and what to do about it? Molecular Psychiatry 17, 1174-1179.

Kaymaz N, Drukker M, Lieb R, Wittchen HU, Werbeloff N, Weiser M, Lataster T, van Os J (2012). Do subthreshold psychotic experiences predict clinical outcomes in unselected non-help-seeking population-based samples? A systematic review and meta-analysis, enriched with new results. Psychological Medicine 42, 2239-2253.

Kaymaz N, van Os J, de Graaf R, Ten Have M, Nolen W, Krabbendam L (2007). The impact of subclinical psychosis on the transition from subclinicial mania to bipolar disorder. Journal of Affective Disorders 98, 55-64.

Kelleher I, Keeley H, Corcoran P, Lynch F, Fitzpatrick C, Devlin N, Molloy C, Roddy S, Clarke MC, Harley M, Arseneault L, Wasserman C, Carli V, Sarchiapone M, Hoven C, Wasserman D, Cannon M (2012). Clinicopathological significance of psychotic experiences in non-psychotic young people: evidence from four population-based studies. British Journal of Psychiatry 201, 26-32.

Kendell R, Jablensky A (2003). Distinguishing between the validity and utility of psychiatric diagnoses. American Journal of Psychiatry 160, 4-12.

Kendler KS (2016a). Phenomenology of schizophrenia and the representativeness of modern diagnostic criteria. JAMA Psychiatry 73, 1082-1092.

Kendler KS (2016b). The transformation of American psychiatric nosology at the dawn of the twentieth century. Molecular Psychiatry 21, 152-158.

Keshavan MS, Nasrallah HA, Tandon R (2011). Schizophrenia, 'Just the Facts' 6. Moving ahead with the schizophrenia concept: from the elephant to the mouse. Schizophrenia Research 127, 3-13.

Kirkpatrick B, Buchanan RW, Ross DE, Carpenter Jr. WT (2001). A separate disease within the syndrome of schizophrenia. Archives of General Psychiatry 58, 165-171.

Kirkpatrick B, Fenton WS, Carpenter Jr. WT, Marder SR (2006). The NIMH-MATRICS consensus statement on negative symptoms. Schizophrenia Bulletin 32, 214-219.

Kirkpatrick B, Galderisi S (2008). Deficit schizophrenia: an update. World Psychiatry 7, 143-147.

Koike S, Yamaguchi S, Ojio Y, Ohta K, Ando S (2016). Effect of name change of schizophrenia on mass media between 1985 and 2013 in Japan: a text data mining analysis. Schizophrenia Bulletin 42, 552-559.

Krabbendam L, Myin-Germeys I, De Graaf R, Vollebergh W, Nolen WA, Iedema J, Van Os J (2004). Dimensions of depression, mania and psychosis in the general population. Psychological Medicine 34, 1177-1186.

Kraemer HC (2007). DSM categories and dimensions in clinical and research contexts. International Journal of Methods in Psychiatric Research 16(Suppl 1), S8-S15.

Kraepelin E (1992). Die Erscheinungsformen des Irreseins: (the manifestations of insanity). History of Psychiatry 3, 509529 .
Lasalvia A, Penta E, Sartorius N, Henderson S (2015). Should the label 'schizophrenia' be abandoned? Schizophrenia Research 162, 276-284.

Leamy M, Bird V, Le Boutillier C, Williams J, Slade M (2011). Conceptual framework for personal recovery in mental health: systematic review and narrative synthesis. British Journal of Psychiatry 199, 445-452.

Lee SH, Ripke S, Neale BM, Faraone SV, Purcell SM, Perlis RH, Mowry BJ, Thapar A, Goddard ME, Witte JS, Absher D, Agartz I, Akil H, Amin F, Andreassen OA, Anjorin A, Anney R, Anttila V, Arking DE, Asherson P, Azevedo MH, Backlund L, Badner JA, Bailey AJ, Banaschewski T, Barchas JD, Barnes MR, Barrett TB, Bass N, Battaglia A, Bauer M, Bayes M, Bellivier F, Bergen SE, Berrettini W, Betancur C, Bettecken T, Biederman J, Binder EB, Black DW, Blackwood DH, Bloss CS, Boehnke M, Boomsma DI, Breen G, Breuer R, Bruggeman R, Cormican P, Buccola NG, Buitelaar JK, Bunney WE, Buxbaum JD, Byerley WF, Byrne EM, Caesar S, Cahn W, Cantor RM, Casas M, Chakravarti A, Chambert K, Choudhury K, Cichon S, Cloninger CR, Collier DA, Cook EH, Coon H, Cormand B, Corvin A, Coryell WH, Craig DW, Craig IW, Crosbie J, Cuccaro ML, Curtis D, Czamara D, Datta S, Dawson G, Day R, De Geus EJ, Degenhardt F, Djurovic S, Donohoe GJ, Doyle AE, Duan J, Dudbridge F, Duketis E, Ebstein RP, Edenberg HJ, Elia J, Ennis S, Etain B, Fanous A, Farmer AE, Ferrier IN, Flickinger $M$, Fombonne E, Foroud T, Frank J, Franke B, Fraser C, Freedman R, Freimer NB, Freitag CM, Friedl M, Frisen L, Gallagher L, Gejman PV, Georgieva L, Gershon ES, Geschwind DH, Giegling I, Gill M, Gordon SD, Gordon-Smith K, Green EK, Greenwood TA, Grice DE, Gross M, Grozeva D, Guan W, Gurling H, De Haan L, Haines JL, Hakonarson H, Hallmayer J, Hamilton SP, Hamshere ML, Hansen TF, Hartmann AM, Hautzinger M, Heath AC, Henders AK, Herms S, Hickie IB, Hipolito M, Hoefels S, Holmans PA, Holsboer F, Hoogendijk WJ, Hottenga JJ, Hultman CM, Hus $\mathrm{V}$, Ingason A, Ising $M$, Jamain $S$, Jones EG, Jones I, Jones L, Tzeng JY, Kahler AK, Kahn RS, Kandaswamy R, Keller MC, Kennedy JL, Kenny E, Kent L, Kim Y, Kirov GK, Klauck SM, Klei L, Knowles JA, Kohli MA, Koller DL, Konte B, Korszun A, Krabbendam L, Krasucki R, Kuntsi J, Kwan P, Landen M, Langstrom N, Lathrop M, Lawrence J, Lawson WB, Leboyer $M$, Ledbetter DH, Lee PH, Lencz T, Lesch KP, Levinson DF, Lewis CM, Li J, Lichtenstein P, Lieberman JA, Lin DY, Linszen DH, Liu C, Lohoff FW, Loo SK, Lord C, Lowe JK, Lucae S, MacIntyre DJ, Madden PA, Maestrini E, Magnusson PK, Mahon PB, Maier W, Malhotra AK, Mane SM, Martin CL, Martin NG, Mattheisen M, Matthews K, Mattingsdal M, McCarroll SA, McGhee KA, McGough JJ, McGrath PJ, McGuffin P, McInnis MG, McIntosh A, McKinney R, McLean AW, McMahon FJ, McMahon WM, McQuillin A, Medeiros H, Medland SE, Meier S, Melle I, Meng F, Meyer J, Middeldorp CM, Middleton L, Milanova V, Miranda A, Monaco AP, Montgomery GW, Moran JL, Moreno-De-Luca D, Morken G, Morris DW, Morrow EM, Moskvina V, Muglia P, Muhleisen TW, Muir WJ, Muller-Myhsok B, Murtha M, Myers RM, Myin-Germeys 
I, Neale MC, Nelson SF, Nievergelt CM, Nikolov I, Nimgaonkar V, Nolen WA, Nothen MM, Nurnberger JI, Nwulia EA, Nyholt DR, O'Dushlaine C, Oades RD, Olincy A, Oliveira G, Olsen L, Ophoff RA, Osby U, Owen MJ, Palotie A, Parr JR, Paterson AD, Pato CN, Pato MT, Penninx BW, Pergadia ML, Pericak-Vance MA, Pickard BS, Pimm J, Piven J, Posthuma D, Potash JB, Poustka F, Propping P, Puri V, Quested DJ, Quinn EM, Ramos-Quiroga JA, Rasmussen HB, Raychaudhuri S, Rehnstrom K, Reif A, Ribases M, Rice JP, Rietschel M, Roeder K, Roeyers H, Rossin L, Rothenberger A, Rouleau G, Ruderfer D, Rujescu D, Sanders AR, Sanders SJ, Santangelo SL, Sergeant JA, Schachar R, Schalling M, Schatzberg AF, Scheftner WA, Schellenberg GD, Scherer SW, Schork NJ, Schulze TG, Schumacher J, Schwarz M, Scolnick E, Scott LJ, Shi J, Shilling PD, Shyn SI, Silverman JM, Slager SL, Smalley SL, Smit JH, Smith EN, Sonuga-Barke EJ, St Clair D, State M, Steffens M, Steinhausen HC, Strauss JS, Strohmaier J, Stroup TS, Sutcliffe JS, Szatmari P, Szelinger S, Thirumalai S, Thompson RC, Todorov AA, Tozzi F, Treutlein J, Uhr M, van den Oord EJ, Van Grootheest G, Van Os J, Vicente AM, Vieland VJ, Vincent JB, Visscher PM, Walsh CA, Wassink TH, Watson SJ, Weissman MM, Werge T, Wienker TF, Wijsman EM, Willemsen G, Williams N, Willsey AJ, Witt SH, Xu W, Young AH, Yu TW, Zammit S, Zandi PP, Zhang P, Zitman FG, Zollner S, Devlin B, Kelsoe JR, Sklar P, Daly MJ, O'Donovan MC, Craddock N, Sullivan PF, Smoller JW, Kendler KS, Wray NR (2013). Genetic relationship between five psychiatric disorders estimated from genome-wide SNPs. Nature Genetics 45, 984-994.

Lewine R, Burbach D, Meltzer HY (1984). Effect of diagnostic criteria on the ratio of male to female schizophrenic patients. American Journal of Psychiatry 141, 84-87.

Lieberman JA, First MB (2007). Renaming schizophrenia. BMJ 334, 108.

Linscott RJ, Allardyce J, van Os J (2010). Seeking verisimilitude in a class: a systematic review of evidence that the criterial clinical symptoms of schizophrenia are taxonic. Schizophrenia Bulletin 36, 811-829.

Linscott RJ, van Os J (2013). An updated and conservative systematic review and meta-analysis of epidemiological evidence on psychotic experiences in children and adults: on the pathway from proneness to persistence to dimensional expression across mental disorders. Psychological Medicine 43, 1133-1149.

Lublin FD, Reingold SC, Cohen JA, Cutter GR, Sorensen PS, Thompson AJ, Wolinsky JS, Balcer LJ, Banwell B, Barkhof F, Bebo Jr. B, Calabresi PA, Clanet M, Comi G, Fox RJ, Freedman MS, Goodman AD, Inglese $M$, Kappos L, Kieseier BC, Lincoln JA, Lubetzki C, Miller AE, Montalban X, O'Connor PW, Petkau J, Pozzilli C, Rudick RA, Sormani MP, Stuve O, Waubant E, Polman CH (2014). Defining the clinical course of multiple sclerosis: the 2013 revisions. Neurology 83, 278-286.

Mancuso SG, Morgan VA, Mitchell PB, Berk M, Young A, Castle DJ (2015). A comparison of schizophrenia, schizoaffective disorder, and bipolar disorder: results from the second Australian national psychosis survey. Journal of Affective Disorders 172, 30-37.

Maric N, Myin-Germeys I, Delespaul P, de Graaf R, Vollebergh W, Van Os J (2004). Is our concept of schizophrenia influenced by Berkson's bias? Social Psychiatry and Psychiatric Epidemiology 39, 600-605.

McAusland L, Buchy L, Cadenhead KS, Cannon TD, Cornblatt BA, Heinssen R, McGlashan TH, Perkins DO, Seidman LJ, Tsuang MT, Walker EF, Woods SW, Bearden CE, Mathalon DH, Addington J (2015). Anxiety in youth at clinical high risk for psychosis. Early Intervention in Psychiatry. In press. doi: 10.1111/eip.12274.

McGlashan TH (1988). A selective review of recent North American long-term followup studies of schizophrenia. Schizophrenia Bulletin 14, 515-542.

McGlashan TH, Zipursky RB, Perkins D, Addington J, Miller TJ, Woods SW, Hawkins KA, Hoffman R, Lindborg S, Tohen M, Breier A (2003). The PRIME North America randomized double-blind clinical trial of olanzapine versus placebo in patients at risk of being prodromally symptomatic for psychosis. I. Study rationale and design. Schizophrenia Research 61, 7-18.

McGorry P, Nelson B (2016). Why we need a transdiagnostic staging approach to emerging psychopathology, early diagnosis, and treatment. JAMA Psychiatry 73, 191-192.

McGorry P, van Os J (2013). Redeeming diagnosis in psychiatry: timing versus specificity. Lancet 381, 343-345.

McGorry PD, Hamilton M, Goldstone S, Rickwood DJ (2016). Response to Jorm: headspace - a national and international innovation with lessons for redesign of mental health care in Australia. Australian and New Zealand Journal of Psychiatry 50, 9-10.

McGorry PD, Yung AR, Phillips LJ, Yuen HP, Francey S, Cosgrave EM, Germano D, Bravin J, McDonald T, Blair A, Adlard S, Jackson H (2002). Randomized controlled trial of interventions designed to reduce the risk of progression to first-episode psychosis in a clinical sample with subthreshold symptoms. Archives of General Psychiatry 59, 921-928.

McGrath J, Saha S, Welham J, El Saadi O, MacCauley C, Chant D (2004). A systematic review of the incidence of schizophrenia: the distribution of rates and the influence of sex, urbanicity, migrant status and methodology. BMC Medicine 2, 13.

McGrath JJ, Saha S, Al-Hamzawi A, Andrade L, Benjet C, Bromet EJ, Browne MO, Caldas de Almeida JM, Chiu WT, Demyttenaere K, Fayyad J, Florescu S, de Girolamo G, Gureje O, Haro JM, Ten Have M, Hu C, Kovess-Masfety V, Lim CC, Navarro-Mateu F, Sampson N, Posada-Villa J, Kendler KS, Kessler RC (2016). The bidirectional associations between psychotic experiences and DSM-IV mental disorders. American Journal of Psychiatry 173, 997-1006.

Milev P, Ho BC, Arndt S, Andreasen NC (2005). Predictive values of neurocognition and negative symptoms on functional outcome in schizophrenia: a longitudinal first-episode study with 7-year follow-up. American Journal of Psychiatry 162, 495-506. 
Miller TJ, McGlashan TH, Rosen JL, Cadenhead K, Cannon T, Ventura J, McFarlane W, Perkins DO, Pearlson GD, Woods SW (2003). Prodromal assessment with the structured interview for prodromal syndromes and the scale of prodromal symptoms: predictive validity, interrater reliability, and training to reliability. Schizophrenia Bulletin 29, 703-715.

Moncrieff J, Middleton H (2015). Schizophrenia: a critical psychiatry perspective. Current Opinion in Psychiatry 28, 264-268.

Morrison AP, French P, Stewart SL, Birchwood M, Fowler D, Gumley AI, Jones PB, Bentall RP, Lewis SW, Murray GK, Patterson P, Brunet K, Conroy J, Parker S, Reilly T, Byrne R, Davies LM, Dunn G (2012). Early detection and intervention evaluation for people at risk of psychosis: multisite randomised controlled trial. BMJ 344, e2233.

Murray RM (1979). A reappraisal of American psychiatry. Lancet 1, 255-258.

Murray RM (2017). Mistakes I have made in my research career. Schizophrenia Bulletin 43, 253-256.

Murray RM, Sham P, Van Os J, Zanelli J, Cannon M, McDonald C (2004). A developmental model for similarities and dissimilarities between schizophrenia and bipolar disorder. Schizophrenia Research 71, 405-416.

Nuevo R, Van Os J, Arango C, Chatterji S, Ayuso-Mateos JL (2013). Evidence for the early clinical relevance of hallucinatory-delusional states in the general population. Acta Psychiatrica Scandinavica 127, 482-493.

Perala J, Suvisaari J, Saarni SI, Kuoppasalmi K, Isometsa E, Pirkola S, Partonen T, Tuulio-Henriksson A, Hintikka J, Kieseppa T, Harkanen T, Koskinen S, Lonnqvist J (2007). Lifetime prevalence of psychotic and bipolar I disorders in a general population. Archives of General

Psychiatry 64, 19-28.

Perlis RH, Uher R, Ostacher M, Goldberg JF, Trivedi MH, Rush AJ, Fava M (2011). Association between bipolar spectrum features and treatment outcomes in outpatients with major depressive disorder. Archives of General Psychiatry 68, 351-360.

Poulton R, Caspi A, Moffitt TE, Cannon M, Murray R, Harrington H (2000). Children's self-reported psychotic symptoms and adult schizophreniform disorder: a 15-year longitudinal study. Archives of General Psychiatry 57, 1053-1058.

Read J, Bentall RP (2012). Negative childhood experiences and mental health: theoretical, clinical and primary prevention implications. British Journal of Psychiatry 200, 89-91.

Reininghaus U, Bohnke JR, Hosang G, Farmer A, Burns T, McGuffin P, Bentall RP (2016). Evaluation of the validity and utility of a transdiagnostic psychosis dimension encompassing schizophrenia and bipolar disorder. British Journal of Psychiatry 209, 107-113.

Reininghaus U, Priebe S, Bentall RP (2013). Testing the psychopathology of psychosis: evidence for a general psychosis dimension. Schizophrenia Bulletin 39, 884-895.

Ritsner MS, Gottesman II (2011). The schizophrenia construct after 100 years of challenges. In Handbook of Schizophrenia Spectrum Disorders, Volume I: Conceptual Issues and Neurobiological Advances (ed. M. S. Ritsner), pp. 1-44. Springer: Dordrecht, The Netherlands.
Robins E, Guze SB (1970). Establishment of diagnostic validity in psychiatric illness: its application to schizophrenia. American Journal of Psychiatry 126, 983-987.

Rossler W, Riecher-Rossler A, Angst J, Murray R, Gamma A, Eich D, van Os J, Gross VA (2007). Psychotic experiences in the general population: a twenty-year prospective community study. Schizophrenia Research 92, 1-14.

Russo M, Levine SZ, Demjaha A, Di Forti M, Bonaccorso S, Fearon P, Dazzan P, Pariante CM, David AS, Morgan C, Murray RM, Reichenberg A (2014). Association between symptom dimensions and categorical diagnoses of psychosis: a cross-sectional and longitudinal investigation. Schizophrenia Bulletin 40, 111-119.

Saha S, Chant D, McGrath J (2007). A systematic review of mortality in schizophrenia: is the differential mortality gap worsening over time? Archives of General Psychiatry 64, 1123-1131.

Saha S, Chant D, McGrath J (2008). Meta-analyses of the incidence and prevalence of schizophrenia: conceptual and methodological issues. International Journal of Methods in Psychiatric Research 17, 55-61.

Saha S, Chant D, Welham J, McGrath J (2005). A systematic review of the prevalence of schizophrenia. PLoS Medicine 2, e141.

Saha S, Scott JG, Varghese D, McGrath JJ (2011). The association between general psychological distress and delusional-like experiences: a large population-based study. Schizophrenia Research 127, 246-251.

Sawa A, Snyder SH (2002). Schizophrenia: diverse approaches to a complex disease. Science 296, 692-695.

Sharifi V, Eaton WW, Wu LT, Roth KB, Burchett BM, Mojtabai R (2015). Psychotic experiences and risk of death in the general population: 24-27 year follow-up of the Epidemiologic Catchment Area study. British Journal of Psychiatry 207, 30-36.

Shevlin M, McElroy E, Bentall RP, Reininghaus U, Murphy J (2017). The psychosis continuum: testing a bifactor mode of psychosis in a general population sample. Schizophrenia Bulletin 43, 133-141.

Smeets F, Lataster T, Dominguez MD, Hommes J, Lieb R, Wittchen HU, van Os J (2012). Evidence that onset of psychosis in the population reflects early hallucinatory experiences that through environmental risks and affective dysregulation become complicated by delusions. Schizophrenia Bulletin 38, 531-542.

Smeets F, Lataster T, van Winkel R, de Graaf R, Ten Have M, van Os J (2013). Testing the hypothesis that psychotic illness begins when subthreshold hallucinations combine with delusional ideation. Acta Psychiatrica Scandinavica 127, 34-47.

Spauwen J, Krabbendam L, Lieb R, Wittchen HU, van Os J (2004). Does urbanicity shift the population expression of psychosis? Journal of Psychiatric Research 38, 613-618.

Spauwen J, Krabbendam L, Lieb R, Wittchen HU, van Os J (2006a). Evidence that the outcome of developmental expression of psychosis is worse for adolescents growing up in an urban environment. Psychological Medicine 36, 407-415. Spauwen J, Krabbendam L, Lieb R, Wittchen HU, van Os J (2006b). Impact of psychological trauma on the development 
of psychotic symptoms: relationship with psychosis proneness. British Journal of Psychiatry 188, 527-533.

Strauss JS, Gift TE (1977). Choosing an approach for diagnosing schizophrenia. Archives of General Psychiatry 34, 1248-1253.

Sullivan G, Mittal D, Reaves CM, Haynes TF, Han X, Mukherjee S, Morris S, Marsh L, Corrigan PW (2015). Influence of schizophrenia diagnosis on providers' practice decisions. Journal of Clinical Psychiatry 76, 1068-1074; quiz 1074.

Takahashi H, Ideno T, Okubo S, Matsui H, Takemura K, Matsuura M, Kato M, Okubo Y (2009). Impact of changing the Japanese term for 'schizophrenia' for reasons of stereotypical beliefs of schizophrenia in Japanese youth. Schizophrenia Research 112, 149-152.

Tamminga CA, Ivleva EI, Keshavan MS, Pearlson GD, Clementz BA, Witte B, Morris DW, Bishop J, Thaker GK, Sweeney JA (2013). Clinical phenotypes of psychosis in the Bipolar-Schizophrenia Network on Intermediate Phenotypes (B-SNIP). American Journal of Psychiatry 170, 1263-1274.

Thomas L (1973). Notes of a biology-watcher. Living language. New England Journal of Medicine 289, 1298-1300.

Thompson A, Singh S, Birchwood M (2016). Views of early psychosis clinicians on discontinuation of antipsychotic medication following symptom remission in first episode psychosis. Early Intervention in Psychiatry 10, 355-361.

Tighe SK, Mahon PB, Potash JB (2011). Predictors of lithium response in bipolar disorder. Therapeutic Advances in Chronic Disease 2, 209-226.

van Os J (2009). A salience dysregulation syndrome. British Journal of Psychiatry 194, 101-103.

van Os J (2013). The dynamics of subthreshold

psychopathology: implications for diagnosis and treatment. American Journal of Psychiatry 170, 695-698.

van Os J (2016). 'Schizophrenia' does not exist. BMJ 352, i375.

Van Os J, Delespaul P (2005). Toward a world consensus on prevention of schizophrenia. Dialogues in Clinical Neuroscience 7, 53-67.

van Os J, Gilvarry C, Bale R, van Horn E, Tattan T, White I, Murray R (2000). Diagnostic value of the DSM and ICD categories of psychosis: an evidence-based approach. UK700 Group. Social Psychiatry and Psychiatric Epidemiology 35, 305-311.

Van Os J, Guloksuz S (2017). A critique of the 'ultra-high risk' and 'transition' paradigm. World Psychiatry 16, 200-206.

van Os J, Linscott RJ, Myin-Germeys I, Delespaul P, Krabbendam L (2009). A systematic review and meta-analysis of the psychosis continuum: evidence for a psychosis proneness-persistence-impairment model of psychotic disorder. Psychological Medicine 39, 179-195.

van Os J, Reininghaus U (2016). Psychosis as a transdiagnostic and extended phenotype in the general population. World Psychiatry 15, 118-124.

van Os J, van der Steen Y, Islam MA, Guloksuz S, Rutten BP, Simons CJ, Investigators G (2017). Evidence that polygenic risk for psychotic disorder is expressed in the domain of neurodevelopment, emotion regulation and attribution of salience. Psychological Medicine 1-17. In press. doi: 10.1017/S0033291717000915. van Os J, Wright P, Murray R (1997). Follow-up studies of schizophrenia I: natural history and non-psychopathological predictors of outcome. European Psychiatry 12(Suppl 5), 327s-341s.

van Rossum I, Dominguez MD, Lieb R, Wittchen HU, van Os J (2011). Affective dysregulation and reality distortion: a 10 -year prospective study of their association and clinical relevance. Schizophrenia Bulletin 37, 561-571.

Van Snellenberg JX, de Candia T (2009). Meta-analytic evidence for familial coaggregation of schizophrenia and bipolar disorder. Archives of General Psychiatry 66, 748-755.

Ventura J, Hellemann GS, Thames AD, Koellner V, Nuechterlein KH (2009). Symptoms as mediators of the relationship between neurocognition and functional outcome in schizophrenia: a meta-analysis. Schizophrenia Research 113, 189-199.

Waddington JL, Scully PJ, Youssef HA (1997).

Developmental trajectory and disease progression in schizophrenia: the conundrum, and insights from a 12-year prospective study in the Monaghan 101. Schizophrenia Research 23, 107-118.

Werbeloff N, Drukker M, Dohrenwend BP, Levav I, Yoffe R, van Os J, Davidson M, Weiser M (2012). Self-reported attenuated psychotic symptoms as forerunners of severe mental disorders later in life. Archives of General Psychiatry 69, 467-475.

Wigman JT, Lin A, Vollebergh WA, van Os J, Raaijmakers QA, Nelson B, Baksheev G, Yung AR (2011). Subclinical psychosis and depression: co-occurring phenomena that do not predict each other over time. Schizophrenia Research 130, 277-281.

Wigman JT, van Nierop M, Vollebergh WA, Lieb R, Beesdo-Baum K, Wittchen HU, van Os J (2012). Evidence that psychotic symptoms are prevalent in disorders of anxiety and depression, impacting on illness onset, risk, and severity -- implications for diagnosis and ultra-high risk research. Schizophrenia Bulletin 38, 247-257.

Wigman JT, van Os J, Abidi L, Huibers MJ, Roelofs J, Arntz A, Kelleher I, Peeters FP (2014). Subclinical psychotic experiences and bipolar spectrum features in depression: association with outcome of psychotherapy. Psychological Medicine 44, 325-336.

Woodberry KA, Seidman LJ, Bryant C, Addington J, Bearden CE, Cadenhead KS, Cannon TD, Cornblatt BA, McGlashan TH, Mathalon DH, Perkins DO, Tsuang MT, Walker EF, Woods SW (2016). Treatment precedes positive symptoms in North American adolescent and young adult clinical high risk cohort. Journal of Clinical Child and Adolescent Psychology 1-10. In press. doi:10.1080/ 15374416.2016.1212361.

Yung AR, Yuen HP, McGorry PD, Phillips LJ, Kelly D, Dell'Olio M, Francey SM, Cosgrave EM, Killackey E, Stanford C, Godfrey K, Buckby J (2005). Mapping the onset of psychosis: the comprehensive assessment of at-risk mental states. Australian and New Zealand Journal of Psychiatry 39, 964-971.

Zipursky RB, Reilly TJ, Murray RM (2013). The myth of schizophrenia as a progressive brain disease. Schizophrenia Bulletin 39, 1363-1372. 